\title{
Molecular and environmental characterization of Noonan syndrome in Morocco reveals a significant association with consanguinity and advanced parental age
}

Ihssane El Bouchikhi ${ }^{1,2^{*}}$ (D), Laila Bouguenouch ${ }^{1}$, Fatima Zohra Moufid ${ }^{1,2}$, Imane Samri $^{1}$, Fatima Abdouss ${ }^{1}$, Moulay Abdelilah Melhouf ${ }^{3}$, Mohammed Iraqui Houssaini ${ }^{4}$, Khadija Belhassan ${ }^{1}$, Samir Atmani ${ }^{5}$ and Karim Ouldim ${ }^{1}$

\begin{abstract}
Background: Noonan syndrome (NS) is one of the most common RASopathies, with an autosomal dominant inheritance. This disorder is caused by a range of genes belonging to the RAS-MAP kinase (rat sarcoma viral oncogene homolog/mitogen-activated protein kinases) pathway, with PTPN11 (protein-tyrosine phosphatase, nonreceptor type 11) being the most involved genetic factor.

The aim of this study is to report PTPN11 mutations found in a cohort of Moroccans with Noonan syndrome, compare the mutation rate with various studies, and statistically assess involvement of prominent risk factors in manifestation of this disorder.

Thirty-one NS patients were screened for PTPN11 mutations using PCR-Sanger sequencing method. Pathogenic effect prediction, for detected variants, was carried out using PROVEAN, MutationTaster2, and HSF programs. Statistical tests were performed with R software. Chi-square and Fisher's exact tests were used in percentage comparisons, while Student's test was used in average comparisons.

Results: We detected five pathogenic mutations, one synonymous variant with a potential altering effect on splicing function, and three novel intronic duplications. PTPN11 mutation rate in our cohort is around 16.13\%. Comparison of this rate with the corresponding rates in various populations shows notably significant differences across continents.

Conclusions: Besides genetic factors, the present study suggests involvement of additional environmental factors, Statistical assessment of clinical data confirms particularly the association of NS manifestation with consanguinity and advanced paternal age, and suggests an eventual implication of advanced maternal age as well.
\end{abstract}

Keywords: Noonan syndrome (NS), PTPN11 mutations, Pathogenic effect prediction, Mutation rate, Consanguinity, Paternal age, Moroccan population, Maternal age

\footnotetext{
* Correspondence: ihssane.elbouchikhi@usmba.ac.ma

'Laboratory of Medical Genetics and Oncogenetics, Hassan II University

Hospital, 30000 Fez, Morocco

${ }^{2}$ Molecular Biology Laboratory, Faculty of Medicine and Pharmacy, Fez,

Morocco

Full list of author information is available at the end of the article
} 


\section{Background}

Noonan syndrome is an autosomal dominant disorder, with an incidence of $1 / 1000-2500$ of live births, which makes it one of the common genetic disorders. The most frequent features characterizing Noonan syndrome are facial dysmorphia (hypertelorism, ptosis, epicanthal folds, low-set posteriorly rotated ears, short, or webbed neck), short stature, congenital heart disease (pulmonary stenosis, septal defects), and skeletal defects (cubitus valgus, pectus excavatum), besides hematological, genitourinary, and neurological anomalies [1].

Noonan syndrome belongs to RASopathies set that includes leopard syndrome, cardio-facio-cutaneous syndrome, and Costello syndrome among others. RASopathies are mainly caused by mutations in RAS-MAP kinase (rat sarcoma viral oncogene homolog/mitogen-activated protein kinases) pathway genes. The most involved genes are PTPN11, SOS1, RAF1, KRAS, BRAF, NRAS, HRAS, SHOC2, CBL, and MEK1 159 [2, 3].

Almost half of Noonan syndrome mutations are clustered in PTPN11 (protein-tyrosine phosphatase, non-receptor type 11) [OMIM 176876]. This gene encodes SHP-2 protein, which is composed of $\mathrm{N}$-amino terminal srchomology 2 domain (N-SH2), phosphotyrosine phosphatase domain (PTP), and C-amino terminal src-homology 2 domain (C-SH2) [3].

In this paper, we, first, expose results of PTPN11 (hotspot exons) mutation screening in a Moroccan cohort with Noonan syndrome, discuss pathogenic impact of detected variants, and compare our mutation rate to a wide range of studies from all over the world. Then, in a second part, we statistically assess the relationship of our NS cohort with prominent risk factors, such as advanced paternal age and consanguinity.

\section{Methods}

\section{Subjects}

Thirty-one patients with Noonan syndrome were enrolled from Medical Genetics and Pediatrics Departments between January 2009 and December 2015. Included patients were selected according to the updated Van Der Burgt criteria [4]. Patients were clinically assessed in Medical Genetics Department, and addressed to Cardio-Pediatrics Unit for Echocardiography. Informed consent was obtained, and personal data and familial history were noted for each patient. Subjects with chromosomal abnormalities were excluded. This study was approved by the local ethic committee (ref. 06/14).

\section{Genetic screening}

Blood samples were collected, and genomic DNAs were extracted from leukocytes using GeneCatcher Magnetic Beads Kit (Invitrogen). Seven hotspot exons of PTPN11 gene were amplified using PCR standard protocol and previously reported primer pairs [5]. Coding regions and exon-intron junctions of exons $2,3,4,7,8,12$, and 13 were directly sequenced using the BigDye Terminator v1.1 Cycle Sequencing Kit (ABI Prism), and analyzed by the 3500Dx Genetic Analyzer v2.3 and the SeqA v5.4 software (Applied Biosystems). Sequences were then aligned via NCBI Nucleotide BLAST tool.

\section{Predictional analysis}

In silico prediction analysis was carried out to assess functional impact of identified variants. For this purpose, we used PROVEAN v1.1 [6, 7] and MutationTaster2 [8] programs in case of non-synonymous variants, and HSF v3.0 program [9] in case of synonymous or intronic variants.

\section{Statistical analysis}

Clinical findings were compared with either previous studies or a random cohort of 29 healthy families questioned for this purpose. Demographic data of these control families match those of the affected group, with sex ratios, geographical origins, and children average ages statistically overlapping. Moreover, the obtained mutational rate in PTPN11 hotspot exons was compared to the corresponding rates from different populations. Percentage comparisons were performed using the Fisher exact and Pearson chi-square tests, while average comparisons were done with Student's test. These tests were carried out using the R software.

\section{Results}

\section{Clinical finding}

The studied population is composed of 14 females (45.2\%) and 17 males (54.8\%). The age range of diagnosed patients was between 1 month and 17 years. Congenital heart disease is observed in $84 \%$. The most frequent subtype is pulmonary valvular stenosis, observed in $71.4 \%$ of cases, followed by atrial septal defect seen in $23.8 \%$, while the least observed cardiac phenotype in our cohort seems to be dilated cardiomyopathy (4.7\%). The consanguinity rate is around 36\%, whereas the average age of patient mothers and fathers at birth is 31 and 40 years, respectively. No abnormal information was noticed from personal or family history. Further details are illustrated in Table 1.

\section{Molecular finding}

In the present work, we screened 31 patients affected by Noonan syndrome for PTPN11 hotspot exon mutations. Sanger sequencing allowed us to detect nine different heterozygous variants, spread as follows: four missense variants found in five patients, one synonymous variant detected in one patient carrying also a missense variant, three novel intronic duplications found in four patients, 
Table 1 Clinical features of patients and mutated populations

\begin{tabular}{|c|c|c|}
\hline Features & Studied population (31 patients ${ }^{a}$ ) & Mutated population $\left(5\right.$ patients $\left.{ }^{a}\right)$ \\
\hline Sex ratio & 1.2 & 1.5 \\
\hline Female & $14(45.2 \%)$ & $3(60 \%)$ \\
\hline Male & $17(54.8 \%)$ & $2(40 \%)$ \\
\hline Patient average age (range) & 6.5 years ( 1 month-17 years) & 7.66 (4 months-13 years) \\
\hline Congenital heart disease & $21(84 \%)$ & $4(80 \%)$ \\
\hline Pulmonary valvular stenosis & $15(71.4 \%)$ & $4(100 \%)$ \\
\hline Atrial septal defect & $5(23 \%)$ & $1(25 \%)$ \\
\hline Dilated cardiomyopathy & $1(4.7 \%)$ & $0(0 \%)$ \\
\hline Normal heart & $4(16 \%)$ & $1(20 \%)$ \\
\hline Consanguinity & $9(36 \%)$ & $3(60 \%)$ \\
\hline \multicolumn{3}{|l|}{ Reproductive average age (range) } \\
\hline Maternal reproductive average age & 31 years $(19-42)$ & 29 years $(22-38)$ \\
\hline Paternal reproductive average age & 40 years (23-49) & 38 years $(30-49)$ \\
\hline
\end{tabular}

${ }^{a}$ May vary depending on the available data (i.e., consanguinity data was available in only 25 patients)

and one recurrent intronic variant detected in five patients. Figures 1 and 2 and Table 2 show more details about these variants.

\section{Functional prediction finding}

PROVEAN and MutationTaster2 predicted respectively deleterious and disease causing effects for D61G, Y63C, A72S, and N308S. Table 3 shows the respective obtained scores.

Human Splicing Finder (HSF) considered the variant $\mathrm{H} 85 \mathrm{H}$ as a potential source of splicing alteration, through creating an exonic splicing silencer (ESS) site and breaking an exonic splicing enhancer (ESE) (Fig. 3), while the intronic variants were predicted to have no pathogenic effect on splicing process.

\section{Statistical analysis}

The mutation rate obtained in our cohort, from PTPN11 hotspot exon screening, was about 16.13\% $(5 / 31)$. We compared this rate to its analogues in different populations from around the world. Table 4 shows the comparison details.

\section{Discussion}

In this paper, we report the spectrum of PTPN11 (hotspot exons) mutations in a cohort of 31 patients affected
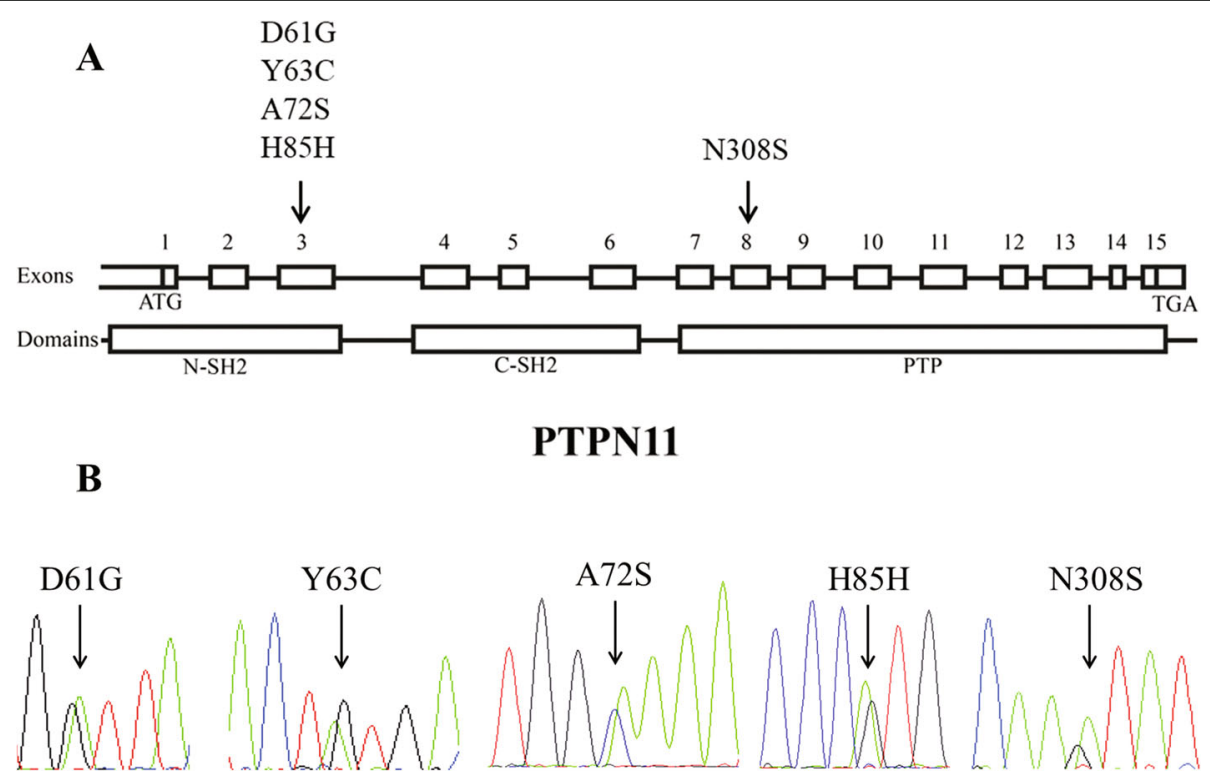

Fig. 1 Localization (a) and sequencing profiles (b) of identified PTPN11 exonic variants 


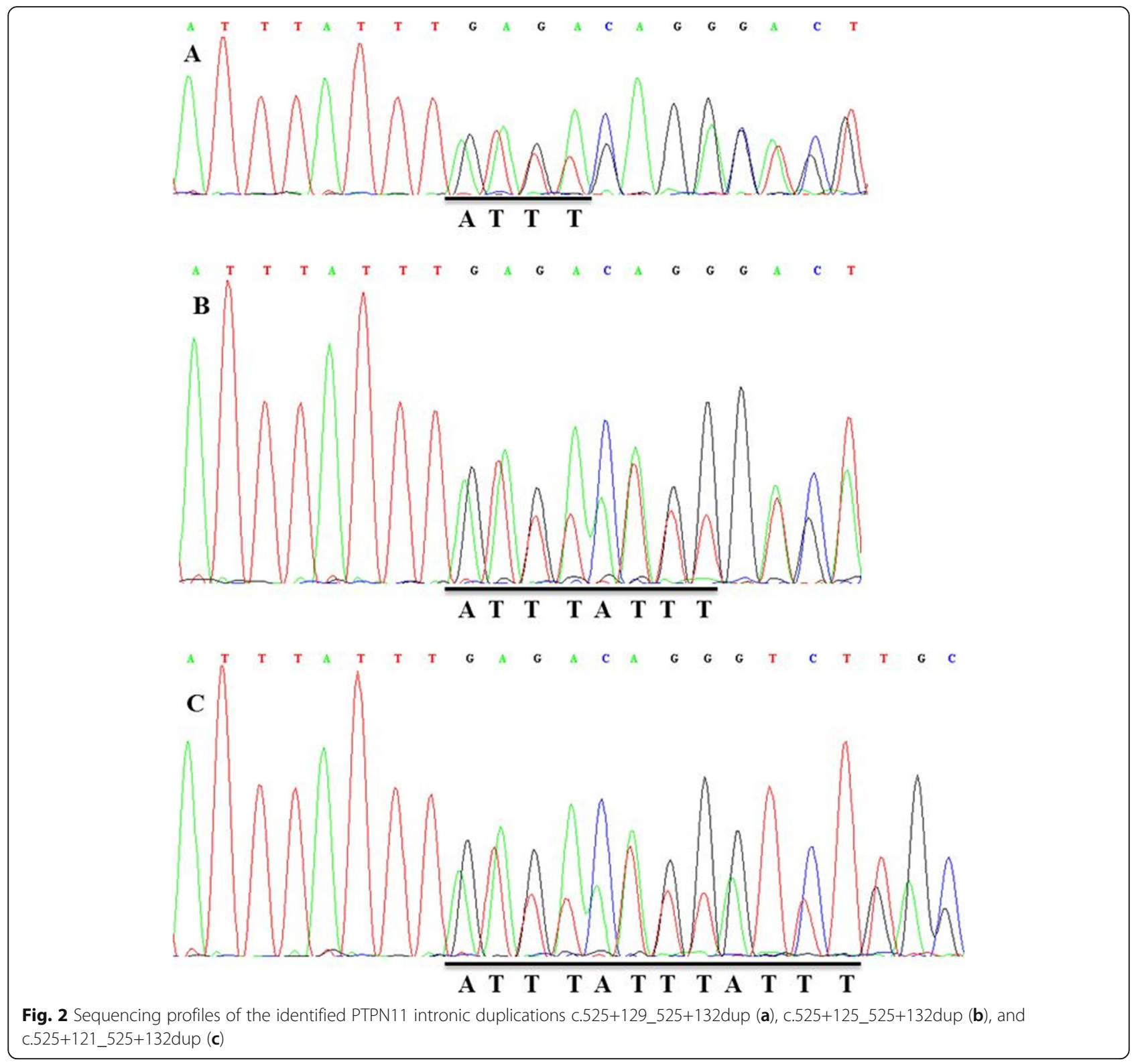

Table 2 Features of identified PTPN11 variants in Noonan population

\begin{tabular}{llllll}
\hline Variant ID & Nucleotide variants & Amino acid variants & Exon/intron & Variant types & Patients \\
\hline rs121918461 & c.182A>G & D61G & Exon 3 & Missense & P10, P11 \\
rs121918459 & c.188A $>$ G & Y63C & Exon 3 & Missense & P5 \\
rs121918453 & c.214G>T & A72S & Exon 3 & Missense & P28 \\
rs61736914 & c.255C>T & H85 $=$ & Exon 3 & Synonymous & P28 \\
Novel & c.525+121_525+132dup & - & Intron 4 & Non-coding duplication & P24 \\
Novel & c.525+125_525+132dup & - & Intron 4 & Non-coding duplication & P21 \\
Novel & c.525+129_525+132dup & - & Intron 4 & Non-coding duplication & P2, P31 \\
rs41279090 & c.854-21C>T & - & Intron 7 & Non-coding substitution & P7, P13, P15, P23, P27 \\
rs121918455 & c.923A>G & N308S & Exon 8 & Missense & P8 \\
\hline
\end{tabular}


Table 3 Pathogenic effect prediction of PROVEAN and MutationTaster2 programs for PTPN11 missense variants

\begin{tabular}{lllll}
\hline Variant & $\begin{array}{l}\text { PROVEAN } \\
\text { score }\end{array}$ & Prediction & $\begin{array}{l}\text { MutationTaster2 } \\
\text { score }\end{array}$ & Prediction \\
\hline D61G & -5.64 & Deleterious & 94 & Disease causing \\
Y63C & -7.06 & Deleterious & 194 & Disease causing \\
A72S & -2.58 & Deleterious & 99 & Disease causing \\
N308S & -4.66 & Deleterious & 46 & Disease causing \\
\hline
\end{tabular}

by Noonan syndrome, discuss their pathogenicity, and compare our mutation rate with various populations throughout the world. In a second part, we assess the clinical data of this cohort, in order to figure out any possible association with a particular epigenetic (nongenetic) risk factor.

\section{Molecular and functional prediction finding}

We have sequenced seven exons $(2,3,4,7,8,12,13)$ that were proved earlier to host $99.9 \%$ of PTPN11 mutations [3], which means that about $1 \%$ of mutations might be overlooked in this study. Three of detected mutations (D61G, Y63C, and A72S) are clustered in the most mutated exon (exon 3). This exon encodes a part of N-SH2 domain, which is involved in interaction with upstream proteins, as well as with phosphotyrosine-phosphatase domain (PTP) to ensure SHP2 self-inhibition. N308S is localized in PTP, which is the SHP2 catalytic domain that ensures the dephosphorylation of phosphor-tyrosine residues of targeted proteins, besides its contribution in SHP2 self-inhibition [24].

Multiple alignment of SHP2 sequence with various species shows that the affected amino acids are highly conserved (Fig. 4). Furthermore, according to in silico prediction tools, D61G, Y63C, A72S, and N308S are deleterious or disease causing. It was shown in different studies that these mutations segregate with the phenotype in the affected families, and was not observed in healthy populations.

This pathogenicity is basically related to the position of the affected residues. In fact, mutations located within, or near to, N-SH2-PTP interaction area seem to disrupt the SHP2 inactive conformation, leading to the exposure of PTP catalytic site, and thus a continuously activated protein $[24,33]$.

Such gain-of-function mutations result in permanent signal transduction through molecular signalization pathway RAS/MAPK (rat sarcoma viral oncogene homolog/ mitogen-activated protein kinase), even in the absence of extra-cell ligand upstream of this pathway.

Since RAS/MAPK is a ubiquitous pathway, involved in proliferation and differentiation of numerous tissues [34,35], mutation disrupting its function could have a drastic impact on various organs, as it is seen in Noonan syndrome features.

In addition to the identified missense mutations, we detected the synonymous variant $\mathrm{H} 85 \mathrm{H}$ (c. $255 \mathrm{C}>\mathrm{T}$ ) in patient P28 who carries A72S mutation as well. Human Splicing Finder (HSF) shows that $\mathrm{H} 85 \mathrm{H}$ may have a potential altering effect on splicing function through impairing splicing regulation consensus motifs. Such effect could entail a loss of a whole exon during the splicing process, resulting in a non-functional truncated protein. Therefore, it is important to conduct functional studies in that particular case to determine whether the observed phenotype is due to a gain-of-function mutation (A72S) or to a loss-of-function mutation $(\mathrm{H} 85 \mathrm{H})$.

Besides these exonic variants, we have detected three novel duplications located in the intronic region, c.525+129_525+132dup, c.525+125_525+132dup, and c.525+121_525+132dup. These duplications concern ATTT motif (Fig. 2) and seem to be mainly due to the presence of a long series of ATTT tandem repeats at this region. According to HSF program, these duplications, in addition to the fourth intronic variant c.854$21 \mathrm{C}>\mathrm{T}$, seem to have no pathogenic effect on splicing.

\section{Statistical finding}

According to these findings, the PTPN11 mutation rate in our study is around $16.13 \%(5 / 31)$. In order to check out the putative involvement of additional environmental factors, we proceeded to the comparison of our rate

\begin{tabular}{|c|c|c|c|}
\hline Predicted signal & Prediction algorithm & cDNA Position & Interpretation \\
\hline \multirow{3}{*}{ New ESS Site } & 1 - ESR Sequences from Goren et al. & \multirow{3}{*}{$A A C A I C A I G G G C A A$} & \multirow{3}{*}{$\begin{array}{l}\text { Creation of an exonic ESS site } \\
\text { Potential alteration of splicing. }\end{array}$} \\
\hline & 2 - IIEs from Zhang et al. & & \\
\hline & 3- Sironi et al. - Motif 2 & & \\
\hline \multirow{4}{*}{ ESE Site Broken } & 1 - ESE-Finder - SF2/ASF & \multirow{4}{*}{ A ACAICACGGGCAAIT } & \multirow{4}{*}{$\begin{array}{l}\text { Alteration of an exonic ESE site. } \\
\text { Potential alteration of splicing. }\end{array}$} \\
\hline & 2 - ESE-Finder - SRp40 & & \\
\hline & 3 - ESE-Finder - SF2/ASF(Ig) & & \\
\hline & 4-EIEs from Zhang et al. & & \\
\hline
\end{tabular}

Fig. 3 Pathogenic effect prediction output of HSF program for synonymous variant His85H 
Table 4 Statistical comparison of PTPN11 hotspot exon mutation rates through worldwide populations

\begin{tabular}{|c|c|c|c|c|}
\hline Continent & $\begin{array}{l}\text { Noonan } \\
\text { population }\end{array}$ & $\begin{array}{l}\text { Mutational rate } \\
\text { of exons } 2,3,4 \text {, } \\
7,8,12 \text { and } 13\end{array}$ & $p$ value $^{*}$ & Reference \\
\hline \multirow[t]{3}{*}{ Africa } & Egyptian & $1 / 21(4.7)$ & 0.4 & [10] \\
\hline & Tunisian & 6/19 (31.6) & 0.3 & [11] \\
\hline & Total & $7 / 40$ (17.5) & 0.8 & - \\
\hline \multirow[t]{10}{*}{ Europe } & Turkish & $6 / 26(23)$ & 0.5 & {$[12]$} \\
\hline & Turkish & $11 / 30(36.7)$ & 0.06 & [13] \\
\hline & Dutch & 56/170 (32.9) & 0.06 & [14] \\
\hline & Italian & 21/71 (29.6) & 0.1 & [15] \\
\hline & Italian & $14 / 40(31.5)$ & 0.07 & [16] \\
\hline & Greek & $17 / 60(28.3)$ & 0.2 & {$[17]$} \\
\hline & German & 16/29 (55) & $0.001^{* *}$ & [18] \\
\hline & German & $34 / 57$ (59.6) & $0.0001^{* *}$ & [19] \\
\hline & German & 23/79 (29) & 0.1 & [20] \\
\hline & Total & 198/562 (35.2) & $0.03^{* *}$ & - \\
\hline \multirow[t]{6}{*}{ America } & Brazilian & 7/14 (50) & $0.03^{* *}$ & [21] \\
\hline & Brazilian & $20 / 50(42)$ & $0.02^{* *}$ & {$[22]$} \\
\hline & American & $54 / 119(45)$ & $0.003^{* *}$ & {$[5]$} \\
\hline & American & $33 / 65(50.7)$ & $0.001^{* *}$ & [23] \\
\hline & American & $11 / 22(50)$ & $0.008^{* *}$ & [24] \\
\hline & Total & $125 / 270(46.3)$ & $0.001^{* *}$ & - \\
\hline \multirow[t]{9}{*}{ Asia } & Taiwanese & 13/34 (38.2) & $0.04^{* *}$ & [25] \\
\hline & Japanese & $7 / 21(33.3)$ & 0.1 & [26] \\
\hline & Japanese & 16/41 (39) & $0.03^{* *}$ & [27] \\
\hline & Japanese & 18/45 (40) & $0.02^{* *}$ & {$[28]$} \\
\hline & Korean & 10/18 (55.6) & $0.003^{* *}$ & [29] \\
\hline & Korean & 23/59 (38.9) & $0.02^{* *}$ & {$[30]$} \\
\hline & Korean & $7 / 14(50)$ & $0.03^{* *}$ & {$[31]$} \\
\hline & Korean & 16/59 (27.1) & 0.2 & {$[32]$} \\
\hline & Total & 110/291 (37.8) & $0.01^{* *}$ & - \\
\hline Total (all studies) & & $440 / 1163(37.8)$ & $0.01^{* *}$ & - \\
\hline Present study & Moroccan & 5/31 (16.1) & - & - \\
\hline
\end{tabular}

${ }^{*}$ Compared to the present study

**Significant difference

with those of different populations from all over the world (Table 4).

Our rate seems to be statistically close to rates of North-African and most of European populations. A significant difference was seen between our rate and all American and most of Asian studies.

The lowest rates are seen in the African countries, $4.7-31.6 \%$. The ranges of rates in European and Asian populations are higher, respectively $23-59.6 \%$ and $27.1-$ $55.6 \%$, while the highest levels are reported in American studies, with rates set between 42 and $50.7 \%$.
In a second step, in order to determine whether these differences are significant or not, we compared, on the one hand, the rates of countries belonging to the same continent with each other, and on the other hand, we compared combined rates of different continents with each other.

The performed comparisons show predominance of statistically close rates between populations from the same continent, and significant differences between most populations belonging to different continents, as well as between continental combined rates.

These variations in PTPN11 mutation rates throughout geographical regions suggest the involvement of, besides genetic factors, further ethnical and/or environmental factors, which widely vary across populations, and may include, among others, the following:

- Eating habits, such as healthy dietary habits in Mediterranean and Asian regions

- Sociocultural and/or religious convictions related to restriction of tobacco and alcohol consumption (i.e., Muslim communities) and favored consanguineous marriages (i.e., tribalist communities)

- Industrialization of countries resulting in more industrialized food, exposure to polluted air, and unhealthy lifestyle in urban zones of developed countries

\section{Clinical findings}

In order to best characterize these environmental factors in our NS cohort, we proceeded to the statistical assessment of available data related notably to consanguinity and parental age at proband birth (Table 1), in comparison either with previous studies or with a Moroccan cohort from general population that we interrogated for this purpose.

The average age of included patients at diagnosis was 6.5 years with a median of 5 years. Sex ratio of our cohort is around 1.2, meaning a higher incidence among males. This seems to be consistent with previous studies $[14,36]$.

Congenital heart disease (CHD) is present in 50 to $90 \%$ of NS cases [37-39]. In our study, $84 \%$ of subjects have $\mathrm{CHD}$, with a predominance of pulmonary valvular stenosis, observed in $71.4 \%$ of subjects, followed by atrial septal defect, then cardiomyopathy which is consistent with previous studies, though some of them reported more, or as many, cardiomyopathies as ASD among Noonan syndrome patients [4, 40, 41].

Consanguinity was noticed in $36 \%$ of patients. This rate seems to be quite high compared to that reported in the Moroccan general population, which is set around $15.25 \%$ [42]. The significant difference $(p=0.01)$ puts the consanguinity among the prominent risk factors of NS occurrence. 


\begin{tabular}{|c|c|c|c|c|c|}
\hline & & & Y63 & & \\
\hline \multicolumn{2}{|l|}{ H.sapiens } & 48 & TLAELVQYYMEHHGQLKEKNGDVIE & 97 & NP_002825.3 \\
\hline \multicolumn{2}{|l|}{ P.troglodytes } & 48 & NGAVTH I KIQNT GDYYYDLYGGEKHATLAELVQYYMEH HGQLKEKNGDVIE & 97 & XP_522535.3 \\
\hline \multicolumn{2}{|l|}{ M.mulatta } & 48 & NGAVTH I KIQNT GDYYYDLYGGEKHAILAELVQYYMEHHGQLKEKNGDVIE & 97 & XP_001110117.1 \\
\hline \multicolumn{2}{|l|}{ C.lupus } & 48 & NGAVTH I KIQNT GDYYY DLYGGEKEATLAELVQYYMEH HGQLKEKNGDVIE & 97 & XP_005636307.1 \\
\hline \multicolumn{2}{|l|}{ B.taurus } & 48 & NGAVTH I KIQNT GDYYYDLYGGEKAAILAELVQYYMEHHGQLKEKNGDVIE & 97 & XP_002694636.2 \\
\hline \multicolumn{2}{|l|}{ M.musculus } & 48 & NGAVTH I KIQNT GDYYYLYGGEKAMILAELVQYYMEHHGQLKEKNGDVIE & 97 & NP_035332.1 \\
\hline \multicolumn{2}{|l|}{ R.norvegicus } & 48 & NGAVTHI KIQNT GDYYIDLYGGEKHATLAELVQYYMEHHGQLKEKNGDVIE & 97 & NP_001171064.1 \\
\hline \multicolumn{2}{|l|}{ G.gallus } & 48 & TGAVTH I KIQNT GDYYYDLYGGEKAATLAELVQYYMEH HGQLKEKNGDVIE & 97 & NP_95 \\
\hline \multicolumn{2}{|l|}{ D.rerio } & 48 & NGAVTHI KIQNTGPYY DLYGGEKAA TLAELVQYYMEH HGQLKEKNGDVIE & 97 & NP_956140.1 \\
\hline \multicolumn{2}{|c|}{ D.melanogaster } & 101 & GNEVTHIKIQNNGDEADLYGGEKAATL PELVQYYMENGE-LKEKNGQAIE & 149 & 99174.1 \\
\hline \multicolumn{2}{|l|}{ A.gambiae } & 50 & GQEVTHIKIQNNGDEFDLYGGEKEATLSELVQYYMENGDQLKEKNGQI IE & 99 & XP_563746.4 \\
\hline H.sapiens & 240 & TDKVI & QGFWEEFETLQQQECKLLYSRKEGQRQENKNKNRYKNILPFDHTRWLHDGDPNEPVSDYI & 319 & NP_OO \\
\hline P.troglodytes & 240 & TDKVI & QGFWEEFETLQQQECKLLYSRKEGQRQENKNKNRYKNILPFDHTRVVLHDGDPNEPVSDYINA & 319 & XP_522535.3 \\
\hline M.mulatta & 240 & TDKVI & QGFWEEFETLQQQECKLLYSRKEGQRQENKNKNRYKNILPFDHTRVLLHDGDPNEPVSDYINA & 319 & XP_001110117.1 \\
\hline C.lupus & 240 & TDKVK & QGFWEEFETLQQQECKLLYSRKEGQRQENKNKNRYKNILPFDHTRVVLHDGDPNEPVSDYINANII IMPEFETKCN & 319 & XP_005636307.1 \\
\hline B.taurus & 240 & TDKVK & QGFWEEFETLQQQECKLLYSRKEGQRQENKNKNRYKNILPFDHTRVVLHDGDPNEPVSDYINANII IMPEFETKCN & 319 & XP_002694636.2 \\
\hline M.musculus & 240 & TDKVK & QGFWEEFETLQQQECKLLYSRKEGQRQENKNKNRYKNILPFDHTRWLHDGDPNEPVSDYINANIIMPEFETKCN & 319 & NP_035332.1 \\
\hline R.norvegicus & 240 & TDKVK & QGFWEEFETLQQQECKLLYSRKEGQRQENKNKNRYKNILPFDHTRVVLHDGDPNEPVSDYINANI IMPEFETKCN & 319 & NP_001171064.1 \\
\hline G.gallus & 240 & TDKVK & QGFWEEFETLQQQECKLLYYSRKEGQRQENKNKNRYKNILPFDHTRVVLHDGDPNEPVSDYINANIIMPEFETKCN & 319 & NP_990299.1 \\
\hline D.rerio & 241 & TDKVK & QGFWEEFETLQQQECKLLYSRKEGQRPENKNKNRYKNILPFDHTRVVLTDGDVNEQGSDYINANI IMPDNEAKSN & 320 & NP_-956140.1 \\
\hline
\end{tabular}

Fig. 4 Multiple alignment profile of SHP2 homologs across different species

The averages of paternal and maternal ages at proband pregnancy, in our study, are 40 and 31 years, respectively. These values were compared with the corresponding averages of a group of 29 mothers and fathers chosen randomly from general population, which are 26 and 33 years, respectively. Comparisons show significant differences in both cases, with $p$ values of 0.03 and 0.01 , respectively. Moreover, in our NS-mutated population, paternal ages were interestingly further higher. Paternal age ranges indeed between 30 and 49 with an average of 38 years and a median of 39 years, which seems to be particularly higher than that found in the study of Tartaglia et al., in which they found that the average paternal age of NS patient births (35.6 years) is significantly higher than the general population analyzed in their study [36]. These findings confirm, on the one hand, the association of advanced paternal age to higher risk of Noonan syndrome occurrence among offspring and suggest, on the other hand, the possible involvement of advanced maternal age as well.

It is worth to mention that the main limitation of the present study is the small size of the studied population. Moreover, due to unavailability of parent DNAs, we could not assess the inheritance pattern of identified variants.

\section{Conclusions}

In conclusion, this work allowed us to identify the pathogenic missense mutations D61G, Y63C, A72S, and N308S, and three novel intronic duplications related to excessive
ATTT tandem repeats (c.525+129_525+132dup, c.525+125_ $525+132$ dup, and c.525+121_525+132dup), in addition to the synonymous variant $\mathrm{H} 85 \mathrm{H}$ that seems to have a potential altering effect on splicing function. The latter variant was detected along with the gain-of-function mutation A72S in the same patient, which needs more investigation to determine the actual molecular cause of the observed phenotype. This study shows that PTPN11 pathogenic mutations are responsible of about $16 \%$ of our NS cohort, and that PTPN11 mutation rates vary significantly across continent, suggesting a potential involvement of environmental factors besides genetic factors. Furthermore, the present study emphasizes particularly the significant association of consanguinity and advanced paternal age with Noonan syndrome manifestation, and suggests, for the first time, the possible involvement of advanced maternal age as well.

Finally, this is the first study, to our knowledge, that takes into consideration most of the previous studies arising from around the world, and compares their mutation rates, which allowed providing preliminary evidence for the potential co-involvement of environmental factors (besides genetic etiology), and this through highlighting the statistically significant differences of mutation rates across geographical regions. A stronger epidemiological study should, obviously, be conducted afterward in a large cohort, in order to confirm these preliminary results and thoroughly study the environmental etiology. 


\section{Abbreviations}

CHD: Congenital heart disease; ESE: Exonic splicing enhancer; ESS: Exonic splicing silencer; HSF: Human Splicing Finder; NS: Noonan syndrome; NSH2: Amino-terminal src-homology 2; PTP: Protein-tyrosine phosphatase; PTPN11: Protein-tyrosine phosphatase, non-receptor type 11; RAS-MAP kinase: Rat sarcoma viral oncogene homolog/mitogen-activated protein kinases; SHP2: Non-receptor protein tyrosine phosphatase 2

\section{Acknowledgements}

We thank the patients and their families for their participation in this study.

\section{Authors' contributions}

The conception and supervision of study were done by IEB, MIH, SA, and KO. The research techniques were contributed by IEB, FA, and FZM. The analysis and interpretation of data were participated by IEB and $\mathrm{MIH}$. The writing of paper was performed by IEB. The critical review was done by FZM. The healthy cohort enrollment and questioning were done by IEB and MAM. The clinical assessments were done by $L B, I S, K B$, and $S A$. All authors have read and approved the final manuscript.

\section{Funding}

This work was financially supported by Hassan II University Hospital and Faculty of Medicine and Pharmacy of Fez, University of Sidi Mohamed Ben Abdellah, Morocco. The funders had no role in any aspect of the study (neither in the design of the study; in the collection, analysis, and interpretation of data; nor in the writing of the manuscript).

\section{Availability of data and materials}

The datasets used and/or analyzed during the current study are available from the corresponding author on reasonable request.

\section{Ethics approval and consent to participate}

This study was approved by the local ethics committee entitled "Comité d'éthique de la Faculté de Médecine et de Pharmacie et du CHU Hassan II de Fès" (located in the Faculty of Medicine and Pharmacy of Fez) under the reference ID: ref. 06/14. Written informed consent was obtained from the participating patients or their tutors.

\section{Consent for publication}

Not applicable.

\section{Competing interests}

The authors declare that they have no competing interests.

\section{Author details}

${ }^{1}$ Laboratory of Medical Genetics and Oncogenetics, Hassan II University Hospital, 30000 Fez, Morocco. ${ }^{2}$ Molecular Biology Laboratory, Faculty of Medicine and Pharmacy, Fez, Morocco. ${ }^{3}$ Department of Obstetrics and Gynecology, Hassan II University Hospital, Fez, Morocco. ${ }^{4}$ Laboratory of Microbial Biotechnology, Faculty of Sciences and Techniques, University of Sidi Mohamed Ben Abdellah, Fez, Morocco. ${ }^{5}$ Medico-surgical Unit of Cardio-pediatrics, Department of Pediatrics, Hassan II University Hospital, Fez, Morocco.

\section{Received: 11 October 2019 Accepted: 20 January 2020}

\section{Published online: 18 February 2020}

\section{References}

1. Allanson JE. Noonan syndrome. In: Cassidy, SB; Allanson J, editor. Management of genetic syndromes. Wiley-Blac. 2010. p. 569-86

2. Tartaglia M, Gelb BD, Zenker M (2011) Noonan syndrome and clinically related disorders. Best Pract Res Clin Endocrinol Metab 25(1):161-179

3. El Bouchikhi I, Belhassan K, Zohra F, Iraqui M, Bouguenouch L, Samri I et al (2016) Noonan syndrome-causing genes: molecular update and an assessment of the mutation rate. Int J Pediatr Adolesc Med 3(4):133-142

4. Bhambhani $\mathrm{V}$, Muenke M (2014) Noonan syndrome. Am Fam Physician 89(1):37-43

5. Tartaglia M, Kalidas K, Shaw A, Song X, Musat DL, Van der Burgt I et al (2002) PTPN11 mutations in Noonan syndrome: molecular spectrum, genotype-phenotype correlation, and phenotypic heterogeneity. Am J Hum Genet 70(6):1555-1563
6. Choi Y, Sims GE, Murphy S, Miller JR, Chan A (2012) Predicting the functional effect of amino acid substitutions and indels. PLoS One 7(10):e46688

7. Choi Y. A fast computation of pairwise sequence alignment scores between a protein and a set of single-locus variants of another protein. In: Proceedings of the ACM Conference on Bioinformatics, Computational Biology and Biomedicine (BCB '12). ACM. N Y; 2012. p. 414-7

8. Schwarz JM, Cooper DN, Schuelke M, Seelow D (2014) MutationTaster2: mutation prediction for the deep-sequencing age. Nat Methods 11(4):361-362

9. Desmet FO, Hamroun D, Lalande M, Collod-Beroud G, Claustres M, Beroud C (2009) Human Splicing Finder: an online bioinformatics tool to predict splicing signals. Nucleic Acids Res 37:e67

10. Essawi ML, Ismail MF, Afifi HH, Kobesiy MM, El Kotoury A, Barakat MM (2013) Mutational analysis of the PTPN11 gene in Egyptian patients with Noonan syndrome. J Formos Med Assoc 112(11):707-712

11. Louati $R$, Abdelmoula NB, Trabelsi I, Abid D, Lissewski C, Kharrat $N$ et al (2014) Clinical and molecular findings of Tunisian patients with RASopathies. Mol Syndromol 5(5):212-217

12. Şimşek-Kiper $P$, Alanay Y, Gülhan B, Lissewski C, Türkyilmaz D, Alehan D et a (2013) Clinical and molecular analysis of RASopathies in a group of Turkish patients. Clin Genet 83(2):181-186

13. Derbent M, Oncel Y, Tokel K, Varan B, Haberal A, YaziCi AC et al (2010) Clinical and hematologic findings in Noonan syndrome patients with PTPN11 gene mutations. Am J Med Genet Part A 152(11):2768-2774

14. Jongmans M, Sistermans EA, Rikken A, Nillesen WM, Tamminga R, Patton M et al (2005) Genotypic and phenotypic characterization of Noonan syndrome: new data and review of the literature. Am J Med Genet 134 A(2):165-170

15. Sarkozy A, Conti E, Seripa D, Digilio M, Grifone N, Tandoi C et al (2003) Correlation between PTPN11 gene mutations and congenital heart defects in Noonan and LEOPARD syndromes. J Med Genet 40:704-708

16. Ferrero GB, Baldassarre $G$, Delmonaco AG, Biamino E, Banaudi E, Carta C et al (2008) Clinical and molecular characterization of 40 patients with Noonan syndrome. Eur J Med Genet [Internet] 51(6):566-572 Available from: https://doi.org/10.1016/j.ejmg.2008.06.011

17. Papadopoulou A, Issakidis M, Gole E, Kosma K, Fryssira H, Fretzayas A et al (2012) Phenotypic spectrum of 80 Greek patients referred as Noonan syndrome and PTPN11 mutation analysis: the value of initial clinical assessment. Eur J Pediatr 171(1):51-58

18. Binder G, Neuer $K$, Ranke MB, Wittekindt NE (2005) PTPN11 mutations are associated with mild growth hormone resistance in individuals with Noonan syndrome. J Clin Endocrinol Metab 90(9):5377-5381

19. Zenker M, Buheitel G, Rauch R, Koenig R, Bosse K, Kress W et al (2004) Genotype-phenotype correlations in Noonan syndrome. J Pediatr 144:368-374

20. Musante L, Kehl HG, Majewski F, Meinecke P, Schweiger S, GillessenKaesbach $G$ et al (2003) Spectrum of mutations in PTPN11 and genotype - phenotype correlation in 96 patients with Noonan syndrome and five patients with cardio-facio-cutaneous syndrome. Eur J Hum Genet 11(2):201-206

21. Ferreira LV, Souza SAL, Arnhold IJP, Mendonca BB, Jorge AAL (2005) PTPN11 (protein tyrosine phosphatase, nonreceptor type 11) mutations and response to growth hormone therapy in children with Noonan syndrome. J Clin Endocrinol Metab 90(9):5156-5160

22. Bertola DR, Pereira AC, Albano LMJ, De Oliveira PSL, Kim CA, Krieger JE (2006) PTPN11 gene analysis in 74 Brazilian patients with Noonan syndrome or Noonan-like phenotype. Genet Test 10(3):186-191

23. Pierpont El, Pierpont ME, Mendelsohn NJ, Roberts AE, Tworog-Dube E, Seidenberg MS (2009) Genotype differences in cognitive functioning in Noonan syndrome. Genes, Brain Behav 8(3):275-282

24. Tartaglia M, Mehler EL, Goldberg R, Zampino G, Brunner HG, Kremer $\mathrm{H}$ et al (2001) Mutations in PTPN11, encoding the protein tyrosine phosphatase SHP-2, cause Noonan syndrome. Nat Genet 29(4):465-468

25. Hung CS, Lin JL, Lee YJ, Lin SP, Chao MC, Lo FS (2007) Mutational analysis of PTPN11 gene in Taiwanese children with Noonan syndrome. J Formos Med Assoc [Internet] 106(2):169-172 Available from: https://doi.org/10.1016/ S0929-6646(09)60235-7

26. Kosaki K, Suzuki T, Muroya K, Hasegawa T, Sato S, Matsuo N et al (2002) PTPN11 (proteintyrosine phosphatase, nonreceptor-type 11) mutations in seven Japanese patients with Noonan syndrome. J Clin Endocrinol Metab 87:3529-3533

27. Niihori T, Aoki Y, Ohashi H, Kurosawa K, Kondoh T, Ishikiriyama S et al (2005) Functional analysis of PTPN11/SHP-2 mutants identified in Noonan syndrome and childhood leukemia. J Hum Genet 50(4):192-202 
28. Yoshida R, Hasegawa T, Hasegawa Y, Nagai T, Kinoshita E, Tanaka Y et al (2004) Protein-tyrosine phosphatase, nonreceptor type 11 mutation analysis and clinical assessment in 45 patients with Noonan syndrome. J Clin Endocrinol Metab 89(7):3359-3364

29. Choi JH, Lee BH, Jung CW, Kim YM, Jin HY, Kim JM et al (2012) Response to growth hormone therapy in children with Noonan syndrome: correlation with or without PTPN11 gene mutation. Horm Res Paediatr 77(6):388-393

30. Lee BH, Kim JM, Jin HY, Kim GH, Choi JH, Yoo HW (2011) Spectrum of mutations in Noonan syndrome and their correlation with phenotypes. J Pediatr [Internet] 159(6):1029-1035 Available from: https://doi.org/10.1016/j. jpeds.2011.05.024

31. Lee ST, Ki CS, Lee HJ (2007) Mutation analysis of the genes involved in the Ras-mitogen-activated protein kinase (MAPK) pathway in Korean patients with Noonan syndrome. Clin Genet 72(2):150-155

32. Ko JM, Kim JM, Kim GH, Yoo HW (2008) PTPN11, SOS1, KRAS, and RAF1 gene analysis, and genotype-phenotype correlation in Korean patients with Noonan syndrome. J Hum Genet 53(11-12):999-1006

33. Hof P, Pluskey S, Dhe-Paganon S, Eck MJ, Shoelson S (1998) Crystal structure of the tyrosine phosphatase SHP-2. Cell. 92:441-450

34. Tamir I, Dal Porto JM, Cambier J (2000) Cytoplasmic protein tyrosine phosphatase SHP-1 and SHP-2: regulators of B cell signal transduction. Curr Opin Immunol 12:307-315

35. Feng G (1999) Shp-2 tyrosine phosphatase: signaling one cell or many. Exp Cell Res 253:47-54

36. Tartaglia M, Cordeddu V, Chang H, Shaw A, Kalidas K, Crosby A et al (2004) Paternal germline origin and sex-ratio distortion in transmission of PTPN11 mutations in Noonan syndrome. Am J Hum Genet 75(3):492-497

37. Allanson J (1987) Noonan syndrome. J Med Genet 24:9-13

38. Patton M (1994) Noonan syndrome: a review. Growth Genet Horm 33(10):1-3

39. Shaw AC, Kalidas K, Crosby AH, Jeffery S, Patton M (2007) The natural history of Noonan syndrome: a long-term follow-up study. Arch Dis Child 92:128-132

40. Jorge AAL, Malaquias AC, Arnhold IJP, Mendonca BB (2009) Noonan syndrome and related disorders: a review of clinical features and mutations in genes of the RAS/MAPK pathway. Horm Res 71(4):185-193

41. Allanson, JE; Roberts A. Noonan syndrome. In: Adam, MP; Ardinger, HH; Pagon R et al., editor. Gene Reviews. University. Washington, Seattle [2001, updated]; 2019. p. 1-36

42. Jaouad IC, Elalaoui SC, Sbiti A, Elkerh F, Belmahi L, Sefiani A (2009) Consanguineous marriages in Morocco and the consequence for the incidence of autosomal recessive disorders. J Biosoc Sci 41(5):575-581

\section{Publisher's Note}

Springer Nature remains neutral with regard to jurisdictional claims in published maps and institutional affiliations.

\section{Submit your manuscript to a SpringerOpen ${ }^{\circ}$ journal and benefit from:}

- Convenient online submission

- Rigorous peer review

- Open access: articles freely available online

- High visibility within the field

- Retaining the copyright to your article

Submit your next manuscript at $\boldsymbol{\nabla}$ springeropen.com 